NASA/TM-2003-212382

\title{
Implementation of an Associative Flow Rule Including Hydrostatic Stress Effects Into the High Strain Rate Deformation Analysis of Polymer Matrix Composites
}

Robert K. Goldberg and Gary D. Roberts

Glenn Research Center, Cleveland, Ohio

Amos Gilat

Ohio State University, Columbus, Ohio 
Since its founding, NASA has been dedicated to the advancement of aeronautics and space science. The NASA Scientific and Technical Information (STI) Program Office plays a key part in helping NASA maintain this important role.

The NASA STI Program Office is operated by Langley Research Center, the Lead Center for NASA's scientific and technical information. The NASA STI Program Office provides access to the NASA STI Database, the largest collection of aeronautical and space science STI in the world. The Program Office is also NASA's institutional mechanism for disseminating the results of its research and development activities. These results are published by NASA in the NASA STI Report Series, which includes the following report types:

- $\quad$ TECHNICAL PUBLICATION. Reports of completed research or a major significant phase of research that present the results of NASA programs and include extensive data or theoretical analysis. Includes compilations of significant scientific and technical data and information deemed to be of continuing reference value. NASA's counterpart of peerreviewed formal professional papers but has less stringent limitations on manuscript length and extent of graphic presentations.

- TECHNICAL MEMORANDUM. Scientific and technical findings that are preliminary or of specialized interest, e.g., quick release reports, working papers, and bibliographies that contain minimal annotation. Does not contain extensive analysis.

- CONTRACTOR REPORT. Scientific and technical findings by NASA-sponsored contractors and grantees.
- CONFERENCE PUBLICATION. Collected papers from scientific and technical conferences, symposia, seminars, or other meetings sponsored or cosponsored by NASA.

- SPECIAL PUBLICATION. Scientific, technical, or historical information from NASA programs, projects, and missions, often concerned with subjects having substantial public interest.

- TECHNICAL TRANSLATION. Englishlanguage translations of foreign scientific and technical material pertinent to NASA's mission.

Specialized services that complement the STI Program Office's diverse offerings include creating custom thesauri, building customized databases, organizing and publishing research results ... even providing videos.

For more information about the NASA STI Program Office, see the following:

- Access the NASA STI Program Home Page at http://www.sti.nasa.gov

- E-mail your question via the Internet to help@sti.nasa.gov

- Fax your question to the NASA Access Help Desk at 301-621-0134

- Telephone the NASA Access Help Desk at 301-621-0390

- Write to:

NASA Access Help Desk

NASA Center for AeroSpace Information 7121 Standard Drive

Hanover, MD 21076 
NASA/TM-2003-212382

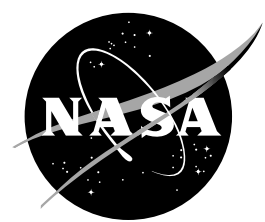

\section{Implementation of an Associative Flow Rule Including Hydrostatic Stress Effects Into the High Strain Rate Deformation Analysis of Polymer Matrix Composites}

Robert K. Goldberg and Gary D. Roberts

Glenn Research Center, Cleveland, Ohio

Amos Gilat

Ohio State University, Columbus, Ohio

National Aeronautics and

Space Administration

Glenn Research Center 
Trade names or manufacturers' names are used in this report for identification only. This usage does not constitute an official endorsement, either expressed or implied, by the National Aeronautics and Space Administration.

The Propulsion and Power Program at NASA Glenn Research Center sponsored this work.

Available from

NASA Center for Aerospace Information 7121 Standard Drive

Hanover, MD 21076
National Technical Information Service 5285 Port Royal Road Springfield, VA 22100

Available electronically at http:/ /gltrs.grc.nasa.gov 


\title{
Implementation of an Associative Flow Rule Including Hydrostatic Stress Effects Into the High Strain Rate Deformation Analysis of Polymer Matrix Composites
}

\author{
Robert K. Goldberg and Gary D. Roberts \\ National Aeronautics and Space Administration \\ Glenn Research Center \\ Cleveland, Ohio 44135 \\ Amos Gilat \\ Ohio State University \\ Columbus, Ohio 43210
}

\section{Summary}

A previously developed analytical formulation has been modified in order to more accurately account for the effects of hydrostatic stresses on the nonlinear, strain rate dependent deformation of polymer matrix composites. State variable constitutive equations originally developed for metals have been modified in order to model the nonlinear, strain rate dependent deformation of polymeric materials. To account for the effects of hydrostatic stresses, which are significant in polymers, the classical $\mathrm{J}_{2}$ plasticity theory definitions of effective stress and effective inelastic strain, along with the equations used to compute the components of the inelastic strain rate tensor, are appropriately modified. To verify the revised formulation, the shear and tensile deformation of two representative polymers are computed across a wide range of strain rates. Results computed using the developed constitutive equations correlate well with experimental data. The polymer constitutive equations are implemented within a strength of materials based micromechanics method to predict the nonlinear, strain rate dependent deformation of polymer matrix composites. The composite mechanics are verified by analyzing the deformation of a representative polymer matrix composite for several fiber orientation angles across a variety of strain rates. The computed values compare well to experimentally obtained results.

\section{Introduction}

NASA Glenn Research Center has an ongoing research project to develop computational methods for the analysis of polymer matrix composites subject to high strain rate impact loads. Under these types of loading conditions, the deformation of the composite can be highly strain rate dependent and nonlinear, which must be accounted for within the analytical model. The deformation of polymer composites is often assumed to be linear elastic and independent of strain rate in transient dynamic finite element codes used for impact analysis (ref. 1).

Polymers are known to have a strain rate dependent deformation response that is nonlinear above about one or two percent strain. Traditionally, viscoelasticity models have been used to capture this behavior (ref. 2). However, there has been an interest in the research community in 
using constitutive equations developed for metals, based on plasticity and viscoplasticity theory, to model the nonlinear, strain rate dependent deformation of polymers and polymer matrix composites. For example, Sun and co-workers (refs. 3, 4) developed a macromechanical, transversely isotropic plasticity theory to analyze the nonlinear deformation of polymer composites. Bordonaro (ref. 5) adapted the viscoplasticity theory based on overstress, originally developed for metals, to analyze the nonlinear deformation of Nylon 66. Pan and co-workers (refs. 6, 7) and Hsu, et al (ref. 8) developed viscoplasticity theories to analyze the nonlinear deformation of polymers including the effect of hydrostatic stresses. In these studies, the effects of hydrostatic stresses on the nonlinear deformation, which unlike in metals are significant for polymers (ref. 9), were accounted for by applying variations of the Drucker-Prager yield criterion (ref. 10) to modify the definitions of the effective stress and the effective inelastic strain. A preliminary effort to account for the effects of hydrostatic stresses on the high strain rate deformation of polymers has been carried out by the authors of this report (ref. 11).

In this paper, constitutive equations with an associated flow rule are developed to analyze the nonlinear, strain rate dependent deformation of polymer matrix materials in which the effects of hydrostatic stresses on the nonlinear deformation response are properly accounted for. The equations developed in previous work (ref. 11) were based on a non-associated flow rule and were found to have difficulties in accurately predicting the multiaxial stress states found in the matrix of a composite material. To calibrate and check the accuracy of the revised equations, two representative toughened epoxy polymers (PR520 and 977-2) are characterized, and the tensile and shear deformation of these materials are modeled for a wide range of strain rates.

The polymer constitutive equations are implemented within a mechanics of materials based micromechanics method incorporating a fiber substructuring approach. This capability permits the analysis of the strain rate dependent, nonlinear deformation of polymer matrix composites. By using this approach, first the matrix constituent is characterized, and its deformation response is computed using the polymer constitutive equations, and then micromechanics equations are applied along with the fiber properties to compute the effective properties and deformation response of the composite. A justification for applying this type of micromechanics approach is that conducting tensile and shear tests on the bulk polymer is much easier than conducting equivalent tests on the composite, particularly at high strain rates and for composites with complicated fiber layups. Therefore, developing a methodology which reduces the amount of testing that is required on the composite, but still can yield strain rate dependent, nonlinear deformation data which can be used by a finite element code, is desirable. In this methodology, the in-situ matrix properties and deformation response are assumed to be equivalent to those of the bulk polymer. This assumption is useful in that it is simpler, due to the number of material constants required for the polymer equations and the procedures used to obtain the constants, to conduct experiments on the pure resin and to determine the resin material constants with this data than it is to try to back out the resin properties from composite test data. However, if in comparing test data obtained from composite specimens to analytical predictions it appears that the bulk matrix properties do not accurately reflect the in-situ state of the matrix, the polymer properties can always be appropriately adjusted. To verify the micromechanics methodology, the tensile deformation of a representative carbon fiber reinforced composite, with one of the polymers used to correlate the constitutive equations (977-2) as its matrix constituent, is analyzed for several fiber orientation angles across a wide range of strain rates. The analytical predictions are compared to experimentally obtained results. 


\section{Polymer Constitutive Equations}

\section{Overview}

To analyze the nonlinear, strain rate dependent deformation of the polymer matrix materials, the Bodner-Partom viscoplastic state variable model (ref. 12), which was originally developed to analyze the viscoplastic deformation of metals above one-half of the melting temperature, is modified. In state variable models, a single unified strain variable is defined to represent all inelastic strains (ref. 13). Furthermore, in the state variable approach there is no defined yield stress. Inelastic strains are assumed to be present at all values of stress, the inelastic strains are just assumed to be very small in the "elastic" range of deformation. State variables, which evolve with stress and inelastic strain, are defined to represent the average effects of the deformation mechanisms.

For this study, temperature and moisture effects have been neglected, as only room temperature data are currently available. These effects will be examined in future efforts. The nonlinear strain recovery observed in polymers on unloading is not currently simulated, and small strain theory is assumed to apply. Phenomena such as creep, relaxation and high cycle fatigue are not currently accounted for within the equations. However, since hydrostatic stress effects have been found to be important in the analysis of high cycle fatigue (ref. 14), correctly accounting for the effects of hydrostatic stresses will be critical if in the future fatigue analysis capabilities are added to the polymer constitutive equations. All of the nonlinearity and strain rate dependence observed in the polymer is assumed in this work to be due to inelastic deformation, where in reality the nonlinearity could be due to a mixture of deformation and damage.

An important point to note for this work is that in the original Bodner model as applied to metals, each of the state variables and material constants had a fairly explicit link to specific deformation mechanisms. In the application of the equations to the analysis of polymers, the relationship of the various constants and variables to specific deformation mechanisms is not as well defined. An internal stress state variable is defined to represent phenomelogically the resistance to molecular flow that takes place during the polymer deformation. An additional state variable is defined which represents phenomelogically the level of influence of the hydrostatic stresses on the inelastic deformation. The remainder of the material constants are characterized in order to match the experimental deformation response of the polymer, and are not tightly linked to specific deformation mechanisms. However, the equations developed here employ a fairly simple formulation with a minimum of easily obtained material constants, and as will be discussed later appear to simulate the nonlinear, strain rate dependent deformation of the polymer fairly accurately both qualitatively and quantitatively.

\section{Associated Flow Equation and Evolution Equations}

In order to derive the associated flow equation for the components of the inelastic strain rate tensor for polymers with hydrostatic stress effects included, a procedure similar to that employed to derive the Prandtl-Reuss equations in classical plasticity is utilized (refs. 10, 13). The formulation employed in this study is based on that used by Pan and co-workers (refs. 6, 7) and Hsu, et al (ref. 8). First, an inelastic potential function based on the Drucker-Prager yield criterion (ref. 10) is defined as

$$
f=\sqrt{J_{2}}+\alpha \sigma_{k k}
$$


where $J_{2}$ is the second invariant of the deviatoric stress tensor. The variable $\sigma_{\mathrm{kk}}$ is the sum of the normal stress components (assuming the usual rules of indicial notation (ref. 13)) and is equal to three times the hydrostatic stress. The variable $\alpha$ is a state variable which controls the level of the hydrostatic stress effects. The term " $\alpha \sigma_{\mathrm{kk}}$ " incorporates the effects of hydrostatic stresses into the inelastic potential function. The components of the inelastic strain rate tensor, $\dot{\varepsilon}_{i j}^{I}$, are assumed to be proportional to the derivative of the potential function with respect to the components of the stress tensor, $\sigma_{\mathrm{ij}}$, as follows

$$
\dot{\varepsilon}_{i j}^{I}=\dot{\lambda} \frac{\partial f}{\partial \sigma_{i j}}
$$

where $\dot{\lambda}$ is a scalar rate variable. By taking the specified derivative of the potential function, the result becomes

$$
\frac{\partial f}{\partial \sigma_{i j}}=\frac{S_{i j}}{2 \sqrt{J_{2}}}+\alpha \delta_{i j}
$$

where $S_{\mathrm{ij}}$ are the components of the deviatoric stress tensor and $\delta_{\mathrm{ij}}$ is the Kronecker delta.

To solve for $\dot{\lambda}$, Equation 3 is substituted into Equation 2, and by multiplying the resulting equation by itself, the following expression is obtained

$$
\dot{\varepsilon}_{i j}^{I} \dot{\varepsilon}_{i j}^{I}=\left(\frac{S_{i j} S_{i j}}{4 J_{2}}+\frac{S_{i j} \delta_{i j}}{\sqrt{J_{2}}} \alpha+\alpha^{2} \delta_{i j} \delta_{i j}\right) \dot{\lambda}^{2}
$$

Equation 4 can be simplified by applying the following easily proven identities

$$
\begin{aligned}
& S_{i j} S_{i j}=2 J_{2} \\
& S_{i j} \delta_{i j}=S_{i i}=0 \\
& \delta_{i j} \delta_{i j}=\delta_{i i}=3
\end{aligned}
$$

which leads to the following expression

$$
\dot{\varepsilon}_{i j}^{I} \dot{\varepsilon}_{i j}^{I}=\dot{\lambda}^{2}\left(\frac{2 J_{2}}{4 J_{2}}+3 \alpha^{2}\right)=\dot{\lambda}^{2}\left(\frac{1+6 \alpha^{2}}{2}\right)
$$

which can be solved for $\dot{\lambda}$ to obtain

$$
\dot{\lambda}=\frac{\sqrt{2 \dot{\varepsilon}_{i j}^{I} \dot{\varepsilon}_{i j}^{I}}}{\sqrt{1+6 \alpha^{2}}}
$$


By substituting Equation 3 and Equation 7 into Equation 2, the associated flow rule can be specified

$$
\dot{\varepsilon}_{i j}^{I}=\frac{\sqrt{2 \dot{\varepsilon}_{i j}^{I} \dot{\varepsilon}_{i j}^{I}}}{\sqrt{1+6 \alpha^{2}}}\left(\frac{S_{i j}}{2 \sqrt{J_{2}}}+\alpha \delta_{i j}\right)
$$

The next step in defining the flow rule is to define the effective stress and the effective inelastic strain rate. The effective stress, $\sigma_{\mathrm{e}}$, is defined as follows

$$
\sigma_{e}=\sqrt{3} f=\sqrt{3 J_{2}}+\sqrt{3} \alpha \sigma_{k k} .
$$

Under pure shear loading, or for cases where the state variable $\alpha$ equals zero, the hydrostatic stress term becomes zero and the effective stress definition reduces to the classical definition of $\sqrt{3 J_{2}}$. To determine the effective inelastic strain rate, $\dot{\varepsilon}_{e}^{I}$, the principal of the equivalence of the inelastic work rate is employed. With the aid of Equations 2 and 3, the inelastic work rate, $\dot{W}^{I}$, can be expressed by the following

$$
\dot{W}^{I}=\sigma_{i j} \dot{\varepsilon}_{i j}^{I}=\sigma_{i j}\left(\frac{S_{i j}}{2 \sqrt{J_{2}}}+\alpha \delta_{i j}\right) \dot{\lambda}=\sigma_{e} \dot{\varepsilon}_{e}^{I} .
$$

After applying the effective stress definition given in Equation 9 and simplifying, it can be shown that

$$
\dot{\lambda}=\sqrt{3} \dot{\varepsilon}_{e}^{I}
$$

which by comparison to Equation 7 leads to a definition for the effective inelastic strain rate

$$
\dot{\varepsilon}_{e}^{I}=\frac{\sqrt{\frac{2}{3} \dot{\varepsilon}_{i j}^{I} \dot{\varepsilon}_{i j}^{I}}}{\sqrt{1+6 \alpha^{2}}} .
$$

By substituting Equation 11 and Equation 3 into Equation 2, an alternative definition for the components of the inelastic strain rate tensor can be given as

$$
\dot{\varepsilon}_{i j}^{I}=\sqrt{3} \dot{\varepsilon}_{e}^{I}\left(\frac{S_{i j}}{2 \sqrt{J_{2}}}+\alpha \delta_{i j}\right) .
$$

By utilizing Equation 13, it can be shown that an alternative definition of the effective inelastic strain rate can be given as 


$$
\begin{aligned}
& \dot{\varepsilon}_{e}^{I}=\dot{e}_{e}^{I}=\sqrt{\frac{2}{3} \dot{e}_{i j}^{I} \dot{e}_{i j}^{I}} \\
& \dot{e}_{i j}^{I}=\dot{\varepsilon}_{i j}^{I}-\dot{\varepsilon}_{m}^{I} \delta_{i j}
\end{aligned}
$$

where $\dot{e}_{e}^{I}$ is the effective deviatoric inelastic strain rate and $\dot{\varepsilon}_{m}^{I}$ is the mean inelastic strain rate, which matches the effective inelastic strain rate definition given by Pan and co-workers (refs. 6 , 7).

By following a similar format to the Bodner-Partom model (refs. 12, 13), the following definition is specified

$$
\frac{\sqrt{3}}{2} \dot{\varepsilon}_{e}^{I}=D_{o} \exp \left[-\frac{1}{2}\left(\frac{Z}{\sigma_{e}}\right)^{2 n}\right]
$$

where $D_{0}$ and $n$ are material constants. $D_{0}$ represents the maximum inelastic strain rate, and $n$ controls the rate dependence of the material. $\mathrm{Z}$ is an isotropic state variable which represents the resistance to molecular flow (internal stress). By substituting Equation 15 into Equation 13, the final form of the flow equation is determined to be

$$
\dot{\varepsilon}_{i j}^{I}=2 D_{o} \exp \left[-\frac{1}{2}\left(\frac{Z}{\sigma_{e}}\right)^{2 n}\right]\left(\frac{S_{i j}}{2 \sqrt{J_{2}}}+\alpha \delta_{i j}\right) .
$$

Note that the elastic components of the strain rate must be added to the inelastic strain rate to obtain the total strain rate.

The rate of evolution of the internal stress state variable $\mathrm{Z}$ and the hydrostatic stress effect state variable $\alpha$ are defined by the equations

$$
\begin{aligned}
& \dot{Z}=q\left(Z_{1}-Z\right) \dot{e}_{e}^{I} \\
& \dot{\alpha}=q\left(\alpha_{1}-\alpha\right) \dot{e}_{e}^{I}
\end{aligned}
$$

where $\mathrm{q}$ is a material constant representing the "hardening" rate, and $\mathrm{Z}_{1}$ and $\alpha_{1}$ are material constants representing the maximum values of $Z$ and $\alpha$, respectively. The initial values of $Z$ and $\alpha$ are defined by the material constants $Z_{\mathrm{o}}$ and $\alpha_{\mathrm{o}}$. The term $\dot{e}_{e}^{I}$ in Equations 17 and 18 represents the effective deviatoric inelastic strain rate, which was defined in Equation 14. An important point to note is that in the original Bodner model (ref. 12), the inelastic work rate was used instead of the effective inelastic strain rate in the evolution equation for the internal stress state variable. However, for this work the inelastic strain rate was deemed easier to work with from both computational and characterization points of view, particularly in the incorporation of hydrostatic stress effects. Furthermore, the effective inelastic strain rate has been used in other state variable constitutive models (ref. 13). Since hydrostatic stress effects were not considered in the original Bodner model (ref. 12), the evolution equation for $\alpha$ is new to this work. The 
state variable $\alpha$ is assumed to evolve in the same manner as the state variable Z. As will be pointed out later, by using this assumption the value of q used in Equation 17 will be the same as the value of q used in Equation 18.

\section{Determination of Material Constants}

The material constants that need to be determined include $\mathrm{D}_{0}, \mathrm{n}, \mathrm{Z}_{\mathrm{o}}, \mathrm{Z}_{1}, \alpha_{0}, \alpha_{1}$, and $\mathrm{q}$. The procedure to be used is summarized here. More details on the general approach can be found in Stouffer and Dame (ref. 13) and Bodner (ref. 12). The values of $\mathrm{D}_{0}, \mathrm{n}$, and $\mathrm{Z}_{1}$ are characterized as follows using Equation 16. The value of $\mathrm{D}_{0}$ is currently assumed to be equal to a value of $10^{4}$ times the maximum applied strain rate, which correlates with the maximum inelastic strain rate. Equation 16 is simplified to the case of pure shear loading, leading to the following expression

$$
\frac{\dot{\gamma}^{I}}{2}=D_{0} \exp \left[-\frac{1}{2}\left(\frac{Z}{\sqrt{3}|\tau|}\right)^{2 n}\right] \frac{\tau}{|\tau|}
$$

where $\dot{\gamma}^{I}$ is the engineering shear strain rate, $\tau$ is the shear stress, and the remainder of the terms are as defined earlier. The case of pure shear loading is used to characterize the equations for two reasons. First, hydrostatic stress effects are not present in the case of pure shear loading, so those material constants do not enter into the picture, simplifying the initial characterization. Second, since polymers tend to be more ductile in shear than in uniaxial tension, the shear stressshear strain curves obtained experimentally are more likely to display a defined "saturation" stress, which as shown below is crucial for determining the material constants. The "saturation", or "yield", stress is defined as the stress level where the inelastic strain rate equals the total applied strain rate. This condition occurs at the point where the stress-strain curve flattens out and becomes horizontal.

Next, Equation 19 is rearranged as follows

$$
-2 \ln \left(\frac{\dot{\gamma}^{I}}{2 D_{0}}\right)=\left(\frac{Z}{\sqrt{3}|\tau|}\right)^{2 n}
$$

and the natural logarithm of both sides of the resulting expression is taken. The values of the inelastic shear strain rate, shear stress, and state variable $\mathrm{Z}$ at "saturation" are substituted into the resulting expression, which yields the following

$$
\ln \left[-2 \ln \left(\frac{\dot{\gamma}_{o}}{2 D_{0}}\right)\right]=2 n \ln \left(Z_{1}\right)-2 n \ln \left(\sqrt{3} \tau_{s}\right)
$$

where $\tau_{\mathrm{s}}$ equals the saturation shear stress, $\dot{\gamma}_{o}$ is the constant applied total engineering shear strain rate in a constant strain rate shear test, and the remaining terms are as defined earlier.

The required constants are determined from a set of shear stress-shear strain curves obtained from constant strain rate tests. Each curve in this set is obtained at a different constant strain 
rate. Data pairs of the total strain rate and saturation shear stress values from each curve are taken. For each strain rate, the data values are substituted into Equation 21, and represent a point on a master curve. The number of points in the master curve equals the number of strain rates at which shear tests were conducted. A least squares regression analysis is then performed on the master curve. As suggested by Equation 21, the slope of the best-fit line is equal to $-2 \mathrm{n}$. The intercept of the best-fit line is equal to $2 \mathrm{n}\left(\ln \left(Z_{1}\right)\right)$.

To determine the value of $Z_{0}$, first Equation 20 is rearranged as follows

$$
Z=\left(-2 \ln \left(\frac{\dot{\gamma}^{I}}{2 D_{o}}\right)\right)^{\frac{1}{2 n}} \sqrt{3} \tau
$$

where all of terms are as defined earlier. To find the value of $Z_{0}$ from Equation 22, the value of the shear stress where the stress-strain curve becomes nonlinear for a particular constant strain rate shear test is used for the value of $\tau$. The point where the stress-strain curve becomes nonlinear is defined as the approximate point where the curve appreciably deviates from a linear extrapolation of the initial data. The value of $\dot{\gamma}^{I}$ is set equal to the approximate inelastic shear strain rate when the stress-strain curve becomes nonlinear. The shear strain rate used in the constant strain rate test divided by 100 was found by trial and error to approximate this value reasonably well. Using this data, Equation 22 is solved for Z, which is assumed to be equal to the value of $Z_{0}$. Using the data from the lowest strain rate test available has been found to give adequate values of $Z_{0}$. However, the calculations can be made using data from all the available strain rates, and an average taken if required to obtain the value of the constant.

To determine the value for q for Equations 17 and 18, first Equation 17 is integrated for the case of pure shear loading, resulting in the following relation

$$
Z=Z_{1}-\left(Z_{1}-Z_{o}\right) \exp \left(\frac{-q}{\sqrt{3}} \gamma^{I}\right)
$$

where $\gamma^{\mathrm{I}}$ is the inelastic shear strain. At saturation, the value of the internal stress $Z$ is assumed to approach $Z_{1}$, resulting in the exponential term approaching zero. Assuming that saturation occurs when the following condition is satisfied

$$
\exp \left(\frac{-q}{\sqrt{3}} \gamma_{s}^{I}\right)=0.01
$$

the equation is solved for $\mathrm{q}$, where $\gamma_{\mathrm{s}}^{\mathrm{I}}$ is the inelastic shear strain at saturation. If the inelastic shear strain at saturation is found to vary with strain rate, the parameter $\mathrm{q}$ is computed at each strain rate and regression techniques are utilized to determine an expression for the variation of q. If Equation 18 is integrated, an expression similar to Equation 23 is obtained. At saturation, the value of $\alpha$ is assumed to approach $\alpha_{1}$, so an equation identical to Equation 24 is obtained, which would lead to the same value for q. Therefore, identical values of q are used in Equation 17 and Equation 18. 
To obtain the values of $\alpha_{1}$ and $\alpha_{0}$, Equation 9 is used in combination with stress-strain data from constant strain rate uniaxial tensile tests and constant strain rate shear tests. The primary assumption used at this point (and assumed implicitly in Equation 9) is that the effective stress at saturation under uniaxial tensile loading at a particular strain rate is equal to the effective stress at saturation under pure shear loading at the same equivalent strain rate. Likewise, the effective stress at the point the stress-strain curve becomes nonlinear under tensile loading is equal to the effective stress at the point the stress-strain curve becomes nonlinear under shear loading. Therefore, assuming the value of $\alpha$ at saturation is equal to $\alpha_{1}$, and the value of $\alpha$ at the point the stress-strain curve becomes nonlinear is equal to $\alpha_{0}$, the following equations are obtained for the case of having data from uniaxial tension tests and pure shear tests

$$
\begin{gathered}
\sigma_{s}\left(1+\sqrt{3} \alpha_{1}\right)=\sqrt{3} \tau_{s} \\
\sigma_{n l}\left(1+\sqrt{3} \alpha_{o}\right)=\sqrt{3} \tau_{n l}
\end{gathered}
$$

where $\sigma_{\mathrm{s}}$ and $\tau_{\mathrm{s}}$ are the tensile and shear stresses at saturation, respectively, and $\sigma_{\mathrm{nl}}$ and $\tau_{\mathrm{nl}}$ are the tensile and shear stresses at the point where the respective stress-strain curves become nonlinear. The required constants can then be determined from these equations. The values of the material constants are assumed to be rate independent, so the results from only one strain rate need to be used to find the needed parameters. In practical application of the methodology, the uniaxial tension and pure shear tests used do not have to be at the exact same effective strain rate. As long as the effective strain rates from the two tests are approximately equal, the values obtained have been found to be valid.

\section{Simulation of Strain Rate Dependent Polymer Deformation}

To demonstrate the ability of the developed constitutive equations to correctly simulate the hydrostatic stress dependent deformation response of polymers, two representative toughened epoxies, PR520 and 977-2, were analyzed. Details of the experimental procedure and experimental results will be given in a future report. However, a summary is given here for completeness. Longitudinal tensile tests and pure shear tests were conducted at room temperature on the materials at strain rates of about $5 \times 10^{-5} / \mathrm{sec}, 1 / \mathrm{sec}$ and $400 / \mathrm{sec}$. The low and moderate strain rate tests were conducted using an Instron hydraulic testing machine. The high strain rate tests were conducted using a split Hopkinson bar. Engineering stress and engineering strain were measured until failure.

Shear stress-shear strain curves for PR520 obtained under pure shear loading are shown in Figure 1 for each of the strain rates examined, while tensile stress-strain curves are shown in Figure 2. Shear stress-shear strain curves for 977-2 are shown in Figure 3, and tensile stressstrain curves are shown in Figure 4. Both materials exhibit a strain rate dependent, nonlinear deformation response under both shear and tensile loading. At high strain rates, the sharp increase in stress at the beginning of the loading with negligible increase in strain observed for both materials under shear loading and for PR520 under tensile loading is most likely the result of a lack of stress equilibrium at the start of loading. Due to this characteristic of the high strain rate shear curves, the initial elastic moduli at high strain rates for both materials were determined by approximations and extrapolations of the data. The oscillations seen in the tensile response of 
977-2 at high strain rates are most likely due to the specimen geometry, leading to stress waves being visible in the response. The tensile specimen design for high strain rate testing was changed between the times when the 977-2 tensile data were obtained and when the PR520 data were obtained, which is why the oscillations do not appear in the PR520 data. The failure stresses under tensile loading for 977-2 appear not to vary with strain rate, and the failure stress for PR520 does not appear to increase in going from the low to the medium strain rates. Preliminary investigations indicate that the measured failure stresses at the higher strain rates may be artificially low due to the presence of strain gages on the specimen and the geometry of the specimen. Further details of these studies will be given in a future report. The material constants for both polymers were determined using the procedures described earlier in this report and are listed in Table 1.

The shear stress-shear strain curves computed for all three strain rates, along with the experimental results for comparison, are shown in Figure 1 for PR520 and Figure 3 for 977-2. Overall, the computed results correlate well with the experimental values for all strain rates for both materials. Specifically, the nonlinearity and rate dependence of the experimental results are captured qualitatively, and the quantitative match between the experimental and computed results is reasonably good. The high strain rate results are somewhat under predicted for both materials (particularly for PR520) at lower strains, but this is most likely due to the fact that in the experiments the initial stresses increased significantly with a negligible increase in strain, and thus the initial modulus of the material was computed by extrapolating from data obtained after the strain became non-negligible.

The tensile stress-strain curves computed for all three strain rates, along with the experimental results for comparison, are shown in Figure 2 for PR520 and Figure 4 for 977-2. For both materials, qualitatively the nonlinearity and rate dependence of the experimental results is captured. Quantitatively, for PR520 at the medium strain rate the stresses in the nonlinear range are somewhat under predicted and for 977-2 at the low strain rate the stresses in the nonlinear range are somewhat over predicted, but otherwise there is a good correlation between the experimental and computed curves. There is not currently a good explanation for the cause of the discrepancies, but the maximum total error is still less than ten percent. The high strain rate tensile stresses for PR520 are somewhat under predicted at lower strains, but this is most likely due to the methods used to determine the initial elastic modulus and the fact that the experimental results showed a sharp increase in stress with negligible increase in strain at low strains. The high strain rate tensile results computed for 977-2 bisect the oscillating experimental curve reasonably well. For the tensile results, the important point to note is that the material constants were primarily computed using the shear data, and the comparison of the computed results to the experimental tensile data is overall still reasonably good.

To further explore the significance of properly accounting for the hydrostatic stress effects in the analysis, the tensile stress-strain curve for PR520 at the low strain rate of $5 \times 10^{-5} / \mathrm{sec}$ is once again considered. In Figure 5, the experimental stress-strain curve, along with the original computed curve ("Alpha Included" in the figure), is presented. A tensile curve computed in which the hydrostatic stress effects are neglected $\left(\alpha_{0}=\alpha_{1}=0\right.$, "Alpha $=0$ " in the figure) is also shown. As can be seen in the figure, when the hydrostatic stress effects are neglected in computing the tensile response, the stresses are significantly over predicted as compared to the experimental results, which indicates that the hydrostatic stress effects are significant for polymers and must be accounted for within an analysis. 


\section{Composite Micromechanical Modeling}

Micromechanics techniques are used to predict the effective properties and deformation response of the individual plies in a composite laminate. The effective properties and deformation response are computed based on the properties of the individual constituents. Lamination theory can then be used to compute the effective deformation response of the entire composite. The constitutive equations described above have been implemented within a micromechanics method in order to enable the prediction of the nonlinear, strain rate dependent deformation response of polymer matrix composites with the effects of hydrostatic stresses incorporated into the analysis. The micromechanics method has been described extensively in Goldberg (ref. 15). A summary of the methodology will be given here.

For this work the unit cell, the smallest material unit for which the response can be considered to be representative of the entire composite ply, is defined to consist of a single fiber and its surrounding matrix. Due to symmetry, only one-quarter of the unit cell is analyzed. The composites are assumed to have a periodic, square fiber packing with a perfect interfacial bond. The fibers are assumed to be transversely isotropic and linear elastic with a circular crosssection. The matrix is assumed to be isotropic, with a rate dependent, nonlinear deformation response computed using the equations described in the previous section of this report. As mentioned previously, the in-situ matrix properties and deformation response are assumed to be equivalent to those of the bulk polymer.

The unit cell is divided up into an arbitrary number of rectangular, horizontal slices of equal thickness, as is shown in Figure 6. Similar approaches have been used by researchers such as Whitney (ref. 16), Greszczuk (ref. 17) and Mital, et al (ref. 18). Each slice is assumed to be in a state of plane stress and classical laminate theory is assumed to be applicable at this scale. The top and bottom slices in the unit cell are composed of pure matrix. The remaining slices are composed of two subslices; one composed of fiber material and the other composed of matrix material. For the slices containing both fiber and matrix, the out-of-plane stresses can be nonzero in individual subslices, but the volume average of the out-of-plane stresses must be equal to zero. By using this approach, the behavior of each slice is decoupled, and the response of each slice can be determined independently, which significantly reduces the level of complexity in the analysis. Laminate theory is used to obtain the effective response of the unit cell. In the future, the ability to incorporate transverse shear stresses and transverse pressures will be added to the model as these loading conditions might be significant in an impact analysis. In this case, the out-of-plane stresses would be constant throughout the unit cell. However, if the capability for out-of-plane loading is added to the model, adjustments to the model might need to be made to account for the fact that by dividing the unit cell using horizontal slicing, the overall unit cell properties might be orthotropic instead of transversely isotropic. In reality, the unit cell properties should be transversely isotropic, but since in the current study only in-plane stresses and loadings are assumed to be present, and the unit cell is assumed to be in a state of plane stress, this possible deficiency in the current model should not be significant.

The thickness, fiber volume ratio and thickness ratio (the ratio of the slice thickness to the total unit cell thickness) for each slice can be determined using the composite fiber volume ratio and geometric principles. The unit cell is assumed to measure one unit in length by one unit in height. The first step is to compute the area of the cross-section of the fiber within each slice. The overall diameter of the fiber $\left(\mathrm{d}_{\mathrm{f}}\right)$ is related to the fiber volume fraction of the overall composite $\left(\mathrm{V}_{\mathrm{f}}\right)$ through the following relationship 


$$
d_{f}=\sqrt{\frac{4 V_{f}}{\pi}}
$$

and this term can be used along with the standard geometric definition of the radius of a circle to compute the horizontal coordinate of any point on the outer surface of the fiber in terms of the fiber volume fraction and the vertical coordinate. The area of the portion of the fiber contained within each slice $\left(A_{f}^{i}\right)$ of the one-quarter of the unit cell which is analyzed can be computed by integrating the resulting expression between the vertical $(\mathrm{z})$ coordinates of the top and bottom of slice "i"

$$
A_{f}^{i}=\int_{z_{i-1}}^{z_{i}} \sqrt{\frac{V_{f}}{\pi}-z^{2}} d z
$$

which is also the equivalent area of the rectangular fiber slice in the one-quarter of the unit cell which is analyzed. The fiber diameter and fiber area within each slice can be used to compute the fiber volume fraction and thickness ratio of each slice.

The effective properties and effective inelastic strains of each slice are computed independently. The responses of each slice are combined using laminate theory to obtain the effective response of the corresponding lamina. Micromechanics equations are developed for those slices composed of both fiber and matrix material. The stresses in the slices composed of pure matrix can be computed using the matrix elastic properties and inelastic constitutive equations. The standard transversely isotropic compliance matrix (or isotropic in the case of the matrix) is used to relate the local strains to the local stresses in the fiber and matrix. Each slice is assumed to be in a state of plane stress on the global level, but out-of-plane normal stresses can exist in each subslice.

Along the fiber direction, the strains are assumed to be uniform in each subslice, and the stresses are combined using volume averaging. The in-plane transverse normal stresses and the in-plane shear stresses are assumed to be uniform in each subslice, and the strains are combined using volume averaging. The out-of-plane strains are assumed to be uniform in each subslice. The volume average of the out-of-plane stresses in each subslice is assumed to be equal to zero, enforcing a plane stress condition on the global level for the slice.

An orthotropic compliance matrix is used to relate the strains to the stresses in each constituent. The inelastic strain components are added to the standard orthotropic elastic compliance matrix to incorporate inelasticity into the constitutive relations. For the fiber, which is assumed to be linear elastic, these components are neglected.

By combining the uniform stress and uniform strain assumptions with the constituent stressstrain relations, a system of four simultaneous equations results that can be solved for the unknown stresses in the subslices. The total strains and subslice inelastic strains are considered to be the known values in solving this problem. By substituting the subslice stresses back into the equations defining the uniform stress assumptions, the effective elastic constants and effective inelastic strains can be computed. By applying classical laminate theory at this point, the effective stiffness matrix and effective inelastic strains for the unit cell are computed. Laminate theory is applied once again to obtain the effective properties and force resultants due 
to inelastic strains for the multilayered composite laminate. Further information on all of these procedures can be found in Goldberg (ref. 15).

\section{Simulation of Strain Rate Dependent Composite Deformation}

To verify the micromechanics equations, and the implementation of the polymer constitutive equations within them, a series of analyses have been carried out using a representative polymer matrix composite system that exhibits a strain rate dependent, nonlinear deformation response. The material examined consists of carbon IM7 fibers in the 977-2 toughened epoxy matrix discussed earlier. Longitudinal tensile tests were conducted until failure on composite laminates with various fiber orientations. Tests were conducted at strain rates of about $5 \times 10^{-5} / \mathrm{sec}$, about $1.0 / \mathrm{sec}$ and about 400-600/sec. Dog-bone shaped specimens were used with a gage length of approximately $0.9525 \mathrm{~cm}$. The low strain rate testing was conducted using an Instron hydraulic testing machine. The high strain rate tests were conducted using a tensile split Hopkinson bar apparatus. More details on the experimental procedures can be found in Gilat, et al (ref. 19).

The IM7/977-2 composite has a fiber volume ratio of 0.60 . The material properties used in this study for the IM7 fiber include a longitudinal modulus of $276 \mathrm{GPa}$, a transverse modulus of 13.8 GPa, a longitudinal Poisson's ratio of 0.25 , a transverse Poisson's ratio of 0.25 and an inplane shear modulus of $20.0 \mathrm{GPa}$. These properties are as given in Gates, et al (ref. 20), with the exception of the value for the transverse Poisson's ratio which was taken from Murthy, et al (ref. 21) based on representative carbon fiber data. The material properties of the 977-2 resin are listed in Table 1. In the computations, five fiber slices were used in the one-quarter of the unit cell which was analyzed. This value was found to yield sufficiently converged answers.

Experimental and computed longitudinal tensile stress-strain curves for three laminate configurations $\left(\left[10^{\circ}\right],\left[45^{\circ}\right]\right.$ and $\left.\left[90^{\circ}\right]\right)$ of the IM7/977-2 material are shown in Figure 7 , Figure 8 and Figure 9. In Figure 7, results for the $\left[10^{\circ}\right]$ laminate at strain rates of $1.8 \times 10^{-5} / \mathrm{sec}, 0.56 / \mathrm{sec}$ and $320 / \mathrm{sec}$ are shown. In Figure 8, results for the $\left[45^{\circ}\right]$ laminate at strain rates of $4.75 \times 10^{-5}$

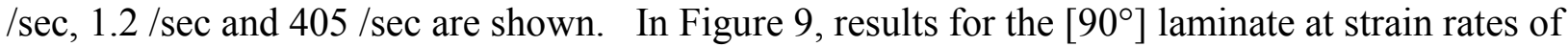
$4.44 \times 10^{-5} / \mathrm{sec}, 1.09 / \mathrm{sec}$ and $405 / \mathrm{sec}$ are shown. Note that the $\left[10^{\circ}\right]$ and $\left[45^{\circ}\right]$ laminates display a strong rate dependency and nonlinearity in the deformation response across the entire range of strain rates. The experimental results for the $\left[90^{\circ}\right]$ laminates at low and medium strain rates show minimal rate dependence and nonlinearity. This lack of rate dependence in the $\left[90^{\circ}\right]$ laminates at lower rates is most likely due to the specimens failing abruptly due to phenomena such as fiber/matrix debonding while the effective stresses in the matrix were still primarily in the elastic range, and the matrix elastic modulus is the same at the low and medium strain rates. The fact that the computed results also predict a mostly linear deformation response seems to support this hypothesis. At high strain rates, the stiffness and maximum stress of the $\left[90^{\circ}\right]$ laminate increase over the values observed at low and medium strain rates. This increase is most likely due to the increase in the matrix modulus observed at high strain rates. The apparent nonlinearity in the experimental stress-strain curve of the $\left[90^{\circ}\right]$ at high strain rates is most likely due to the lack of stress equilibrium at low strains and the specimen geometry.

As can be seen in the figures, the analytical model captures the strain rate dependence (or lack thereof for the $\left[90^{\circ}\right]$ laminates at low strain rates) and nonlinearity observed in the experimental stress-strain curves. Quantitatively, overall the comparison between the experimental and analytical results is quite good. The stresses for the $\left[45^{\circ}\right]$ and $\left[90^{\circ}\right]$ laminates at high strain rates are somewhat under predicted at low strains. There are several possible 
causes for this discrepancy. First, particularly for the $\left[45^{\circ}\right]$ laminate, recall that due to the nature of the tests on the bulk matrix the initial matrix elastic modulus at high strain rates was approximated. The modulus which was determined for high strain rate conditions might be too low. There also could be a lack of stress equilibrium in the experiments at low strains, which could lead to the experimental stresses being too high. The lack of stress equilibrium at low strains in the experimental tests is probably more significant for the $\left[90^{\circ}\right]$ laminate. This particular laminate orientation is dominated by the matrix. Recall that in the high strain rate tensile tests for this matrix material, in which a similar specimen geometry was used, the tensile stress-strain curves displayed a significant oscillation. If an improved specimen geometry was employed for the high strain rate tensile tests of the $\left[90^{\circ}\right]$ laminate, similar to the specimen geometry used in the high strain rate tensile tests for the PR520 resin, the oscillations in the experimental stress-strain curves would most likely be significantly reduced, and the match between the experimental and computed results would most likely be much improved. However, at higher strains for both the $\left[45^{\circ}\right]$ and $\left[90^{\circ}\right]$ laminates the experimental and computed results match reasonably well. In the prediction of composite damage and failure, which will be a future goal of this research, correctly predicting the composite stresses at higher strain levels will be important.

To further explore the significance of properly accounting for the hydrostatic stress effects in the composite analysis, the tensile stress-strain curve for the $\left[45^{\circ}\right]$ laminate at the low strain rate of $4.75 \times 10^{-5} / \mathrm{sec}$ is once again considered. In Figure 10, the experimental stress-strain curve, along with the original computed curve ("Alpha Included" in the figure), is presented. A tensile curve computed in which the hydrostatic stress effects are neglected $\left(\alpha_{0}=\alpha_{1}=0\right.$, "Alpha $=0$ " in the figure) is also shown. As can be seen in the figure, when the hydrostatic stress effects are neglected in computing the tensile response, the stresses are significantly over predicted as compared to the experimental results, similar to what was observed in the bulk polymer. These results indicate that the hydrostatic stress effects are significant for the analysis of polymer matrix composites as well as bulk polymers and must be accounted for within an analysis.

\section{Conclusions}

The Bodner-Partom viscoplastic state variable model (ref. 12) has been modified in order to analyze the strain rate dependent, nonlinear deformation of polymeric matrix materials. The effects of hydrostatic stresses on the inelastic deformation have been accounted for by modifying the effective stress and effective inelastic strain definitions given in the original equations. The material constants are determined solely through the use of simple tension and shear tests. Furthermore, the effects of the hydrostatic stresses are assumed to vary over the course of the loading process, which leads to an improved correlation with experimental results. The tensile and shear deformation response of two representative bulk polymers over a range of strain rates have been successfully predicted. The constitutive equations have been implemented within a strength of materials based micromechanics approach in which the unit cell is subdivided into a set of independently analyzed slices. The micromechanics technique was used to predict the strain rate dependent deformation of a representative polymer matrix composite for three fiber orientations. Qualitatively, the strain rate dependence and nonlinearity observed in experimental stress-strain curves was captured. Quantitatively, at low and medium strain rates the experimental stress-strain curves were accurately predicted by the analytical model. At high strain rates, there were some discrepancies at lower strain levels between the experimental and 
computed results, most likely primarily due to issues in the experimental tests. Overall, the analysis methods presented here appear to correctly capture the important features of the nonlinear, strain rate dependent deformation response of polymers and polymer matrix composites.

The analytical methods described in this study can be used in explicit finite element codes to provide a more realistic analysis of deformation during impact events for composite materials. The analytical model is computationally efficient so that it is feasible to use in the explicit finite element analysis of large composite structures.

\section{References}

1. Anonymous: LS-DYNA Keyword User's Manual, Version 950. Livermore Software Technology Corporation, Livermore, CA, 1997.

2. Wineman, A.S.; and Rajagopal, K.R.: Mechanical Response of Polymers. Cambridge University Press, New York, 2000.

3. Weeks, C.A.; and Sun, C.T.: "Modeling Non-Linear Rate-Dependent Behavior in FiberReinforced Composites.” Composites Science and Technology, Vol. 58, pp. 603-611, 1998.

4. Thiruppukuzhi, S.V.; and Sun, C.T.: "Testing and modeling high strain rate behavior of polymeric composites.” Composites Part B, Vol. 29B, pp. 535-546, 1998.

5. Bordonaro, C.M.: "Rate Dependent Mechanical Behavior of High Strength Plastics: Experiment and Modeling." PhD Dissertation, Rensselaer Polytechnic Institute, Troy, New York, 1995.

6. Li, F.Z; and Pan, J.: "Plane-Stress Crack-Tip Fields for Pressure-Sensitive Dilatant Materials." Journal of Applied Mechanics, Vol. 57, pp. 40-49, 1990.

7. Chang, W.J.; and Pan, J.: "Effects of Yield Surface Shape and Round-Off Vertex on Crack-Tip Fields for Pressure-Sensitive Materials." International Journal of Solids and Structures, Vol. 34, pp. 3291-3320, 1997.

8. Hsu, S.-Y., Vogler, T.J.; and Kyriakides, S.: "Inelastic behavior of an AS4/PEEK composite under combined transverse compression and shear. Part II: modeling." International Journal of Plasticity, Vol. 15, pp. 807-836, 1999.

9. Ward, I.M.: Mechanical Properties of Solid Polymers. John Wiley and Sons, New York, 1983.

10. Khan, A.S.; and Huang, S.: Continuum Theory of Plasticity. John Wiley and Sons, Inc., New York, 1995.

11. Goldberg, R.K.; Roberts, G.D.; and Gilat, A: "Incorporation of Mean Stress Effects Into the Micromechanical Analysis of the High Strain Rate Response of Polymer Matrix Composites." Composites Part B, Vol. 34, pp. 151-165, 2003.

12. Bodner, S.R.: Unified Plasticity for Engineering Applications. Kluwer Academic/Plenum Publishers, New York, 2002.

13. Stouffer, D.C.; and Dame, L.T.: Inelastic Deformation of Metals. Models, Mechanical Properties and Metallurgy. John Wiley and Sons, New York, 1996.

14. Dowling, N.E.: Mechanical Behavior of Materials. Engineering Methods for Deformation, Fracture and Fatigue, Second Edition. Prentice Hall, Upper Saddle River, New Jersey, 1999. 
15. Goldberg, R.K.: "Implementation of Fiber Substructuring Into Strain Rate Dependent Micromechanics Analysis of Polymer Matrix Composites.” NASA/TM-2001-210822, National Aeronautics and Space Administration, Washington, D.C., 2001.

16. Whitney, J.M.: "A Laminate Analogy for Micromechanics." Proceedings of the American Society for Composites Eighth Technical Conference, G.M. Newaz, ed., Technomic Publishing Co., Lancaster, PA, pp. 785-794, 1993.

17. Greszcuk, L.B.: "Interfiber Stresses in Filamentary Composites." AIAA Journal, Vol. 9, pp. 1274-1280, 1971.

18. Mital, S.K.; Murthy, P.L.N.; and Chamis, C.C.: "Micromechanics for Ceramic Matrix Composites Via Fiber Substructuring." Journal of Composite Materials, Vol. 29, pp. 614633, 1995.

19. Gilat, A.; Goldberg, R.K.; and Roberts, G.D.: "Experimental Study of Strain-RateDependent Behavior of Carbon/Epoxy Composite." Composites Science and Technology, Vol. 62, pp. 1469-1476, 2002.

20. Gates, T.S.; Chen, J.-L.; and Sun, C.T.: "Micromechanical Characterization of Nonlinear Behavior of Advanced Polymer Matrix Composites.” Composite Materials: Testing and Design (Twelfth Volume), ASTM STP 1274, R.B. Deo and C.R. Saff, eds., ASTM, pp. 295-319, 1996.

21. Murthy, P.L.N.; Ginty, C.A.; and Sanfeliz, J.G.: "Second Generation Integrated Composite Analyzer (ICAN) Computer Code." NASA TP-3290, National Aeronautics and Space Administration, Washington, D.C., 1993. 


\section{TABLE 1.-MATERIAL PROPERTIES FOR POLYMER MATRIX MATERIALS}

\begin{tabular}{|c|c|c|c|c|c|c|c|c|c|c|}
\hline & $\begin{array}{c}\text { Strain } \\
\text { Rate/sec }\end{array}$ & $\begin{array}{l}\text { Modulus } \\
\text { GPa }\end{array}$ & $\begin{array}{c}\text { Poisson's } \\
\text { Ratio }\end{array}$ & $\begin{array}{c}\mathrm{D}_{\mathrm{o}} \\
1 / \mathrm{sec}\end{array}$ & $\mathrm{n}$ & $\begin{array}{c}\mathrm{Z}_{\mathrm{o}} \\
\mathrm{MPa}\end{array}$ & $\begin{array}{c}\mathrm{Z}_{1} \\
\mathrm{MPa}\end{array}$ & $q$ & $\alpha_{o}$ & $\alpha_{1}$ \\
\hline \multirow{3}{*}{ PR520 } & $7 \times 10^{-5}$ & 3.54 & \multirow{3}{*}{0.38} & \multirow{3}{*}{$1 \times 10^{6}$} & \multirow{3}{*}{0.93} & \multirow{3}{*}{396.09} & \multirow{3}{*}{753.82} & \multirow{3}{*}{279.26} & \multirow{3}{*}{0.568} & \multirow{3}{*}{0.126} \\
\hline & 1.76 & 3.54 & & & & & & & & \\
\hline & 420 & 7.18 & & & & & & & & \\
\hline \multirow{3}{*}{$977-2$} & $9 \times 10^{-5}$ & 3.52 & \multirow{3}{*}{0.40} & \multirow{3}{*}{$1 \times 10^{6}$} & \multirow{3}{*}{0.85} & \multirow{3}{*}{259.50} & \multirow{3}{*}{1131.4} & \multirow{3}{*}{150.50} & \multirow{3}{*}{0.129} & \multirow{3}{*}{0.152} \\
\hline & 1.9 & 3.52 & & & & & & & & \\
\hline & 500 & 6.33 & & & & & & & & \\
\hline
\end{tabular}

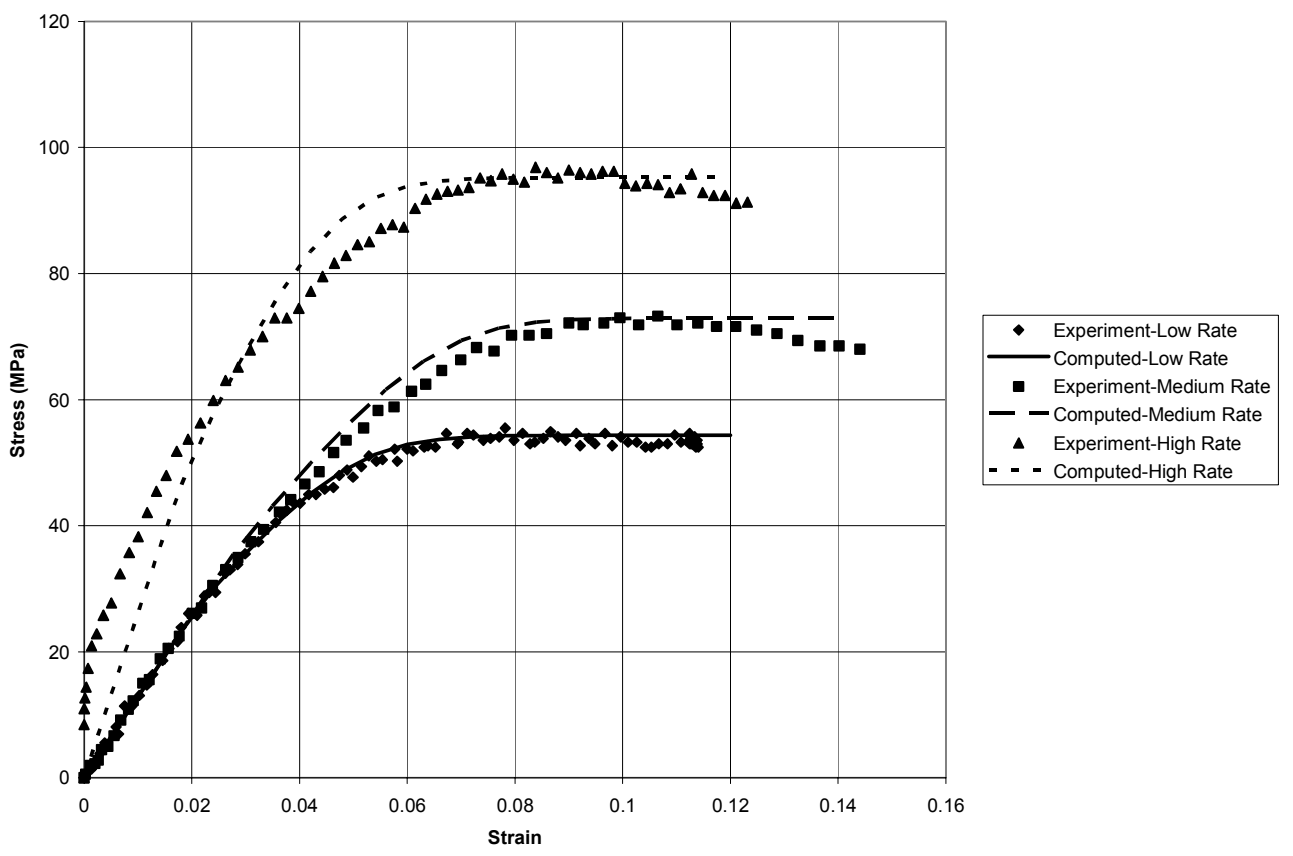

Figure 1.-Experimental and computed shear stress-shear strain curves for PR520 resin at strain rates of $7 \times 10^{-5} / \mathrm{sec}$ (Low Rate), $1.76 / \mathrm{sec}$ (Medium Rate), and $420 / \mathrm{sec}$ (High Rate). 


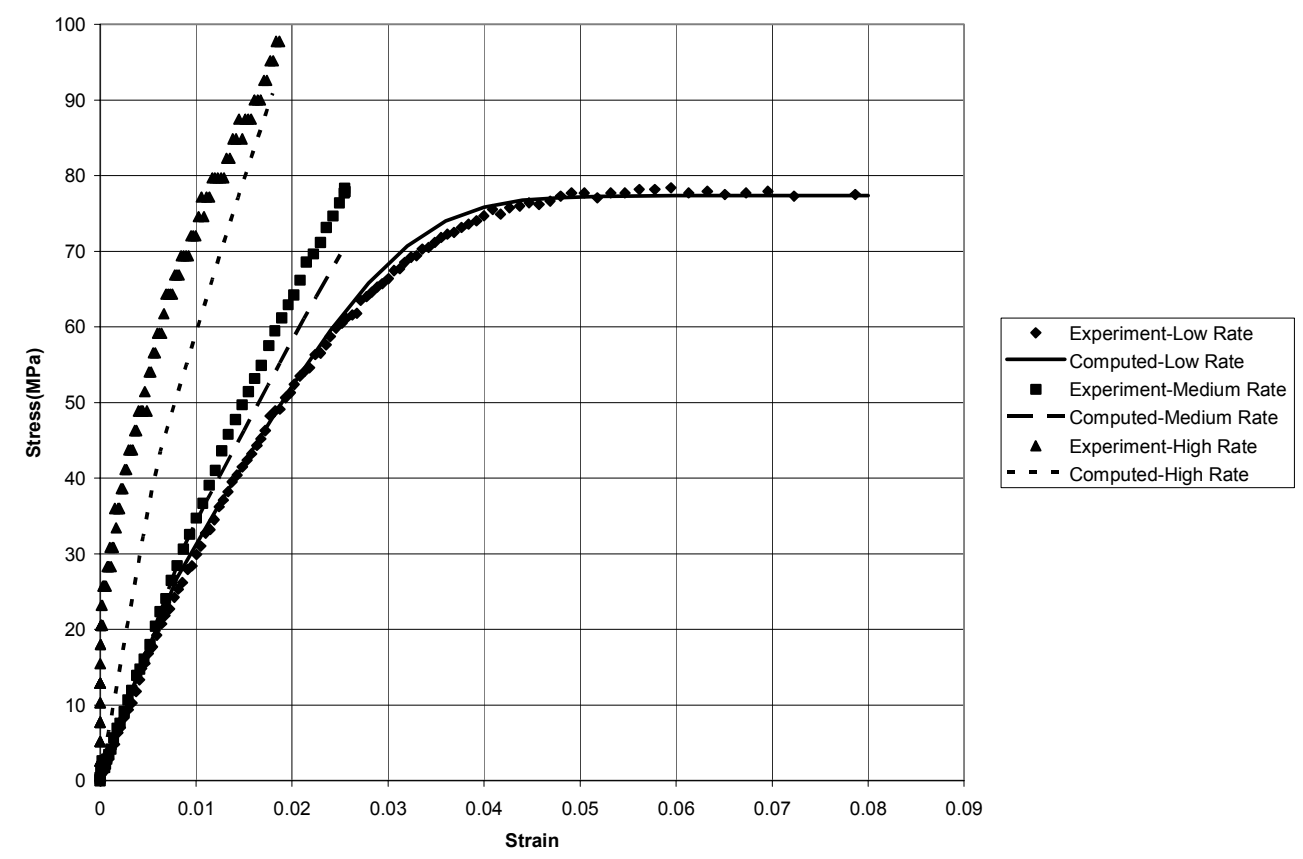

Figure 2.-Experimental and computed tensile stress-strain curves for PR520 resin at strain rates of $5 \times 10^{-5} / \mathrm{sec}$ (Low Rate), 1.4 /sec (Medium Rate) and $510 / \mathrm{sec}$ (High Rate).

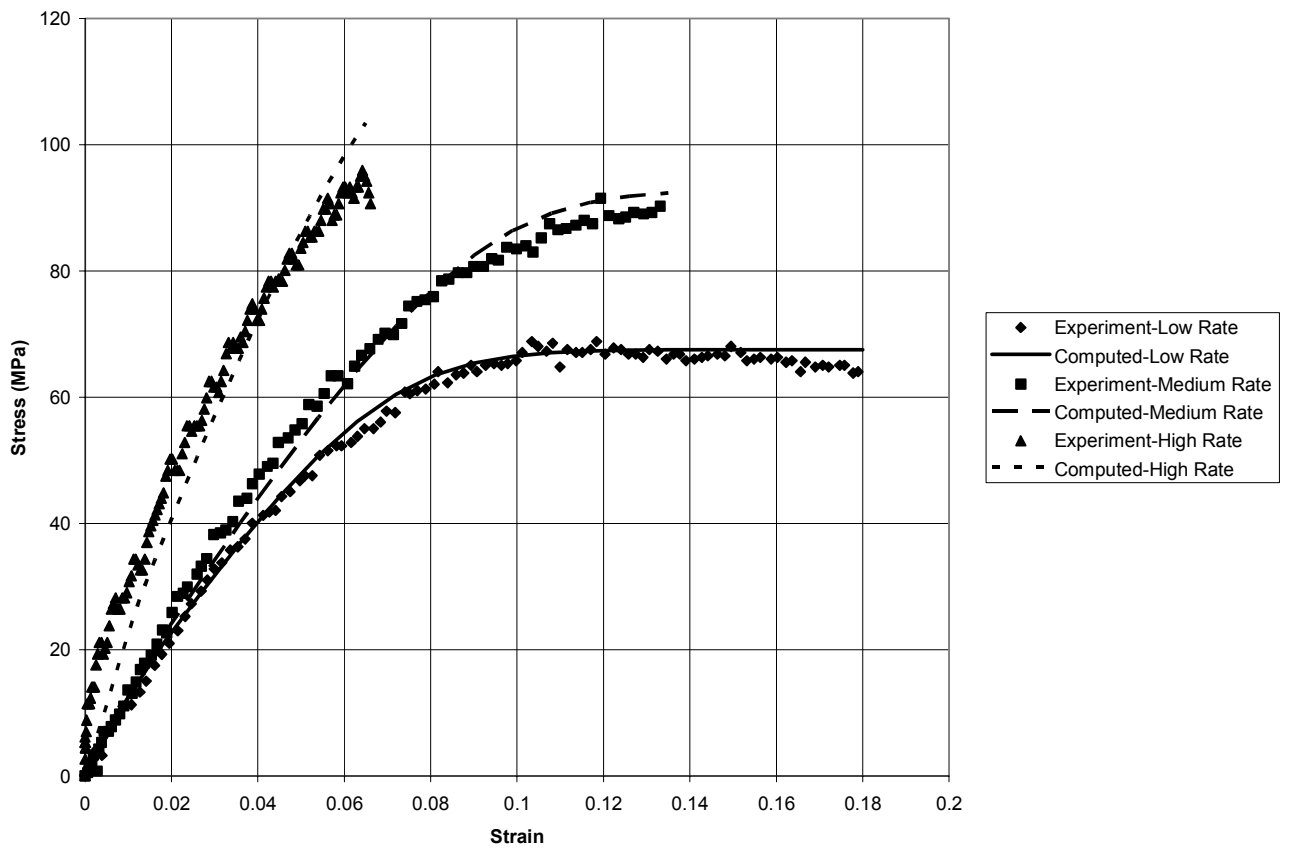

Figure 3.-Experimental and computed shear stress-shear strain curves for 977-2 resin at strain rates of $9 \times 10^{-5} / \mathrm{sec}$ (Low Rate), $1.91 / \mathrm{sec}$ (Medium Rate) and $518 / \mathrm{sec}$ (High Rate). 


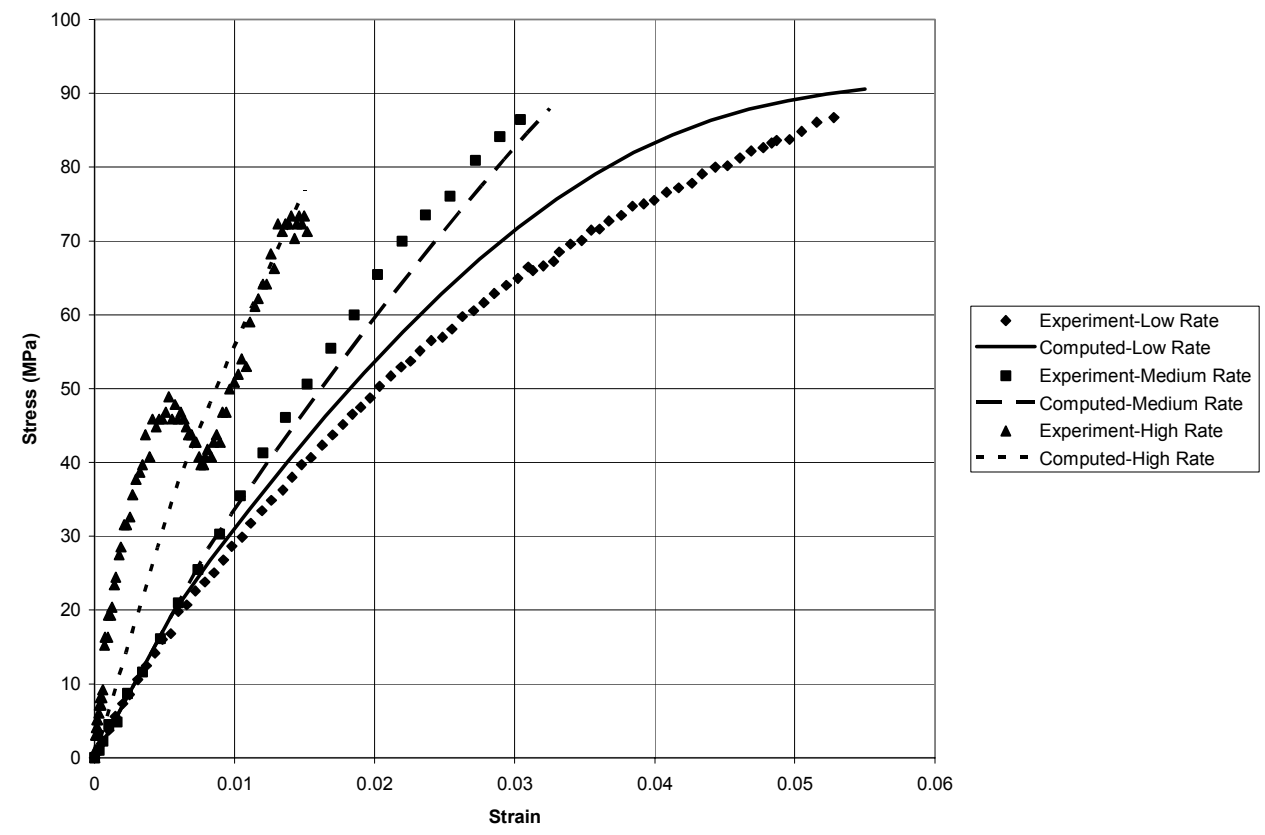

Figure 4.-Experimental and computed tensile stress-strain curves for 977-2 resin at strain rates of $5.7 \times 10^{-5} / \mathrm{sec}$ (Low Rate), $1.31 / \mathrm{sec}$ (Medium Rate) and $365 / \mathrm{sec}$ (High Rate).
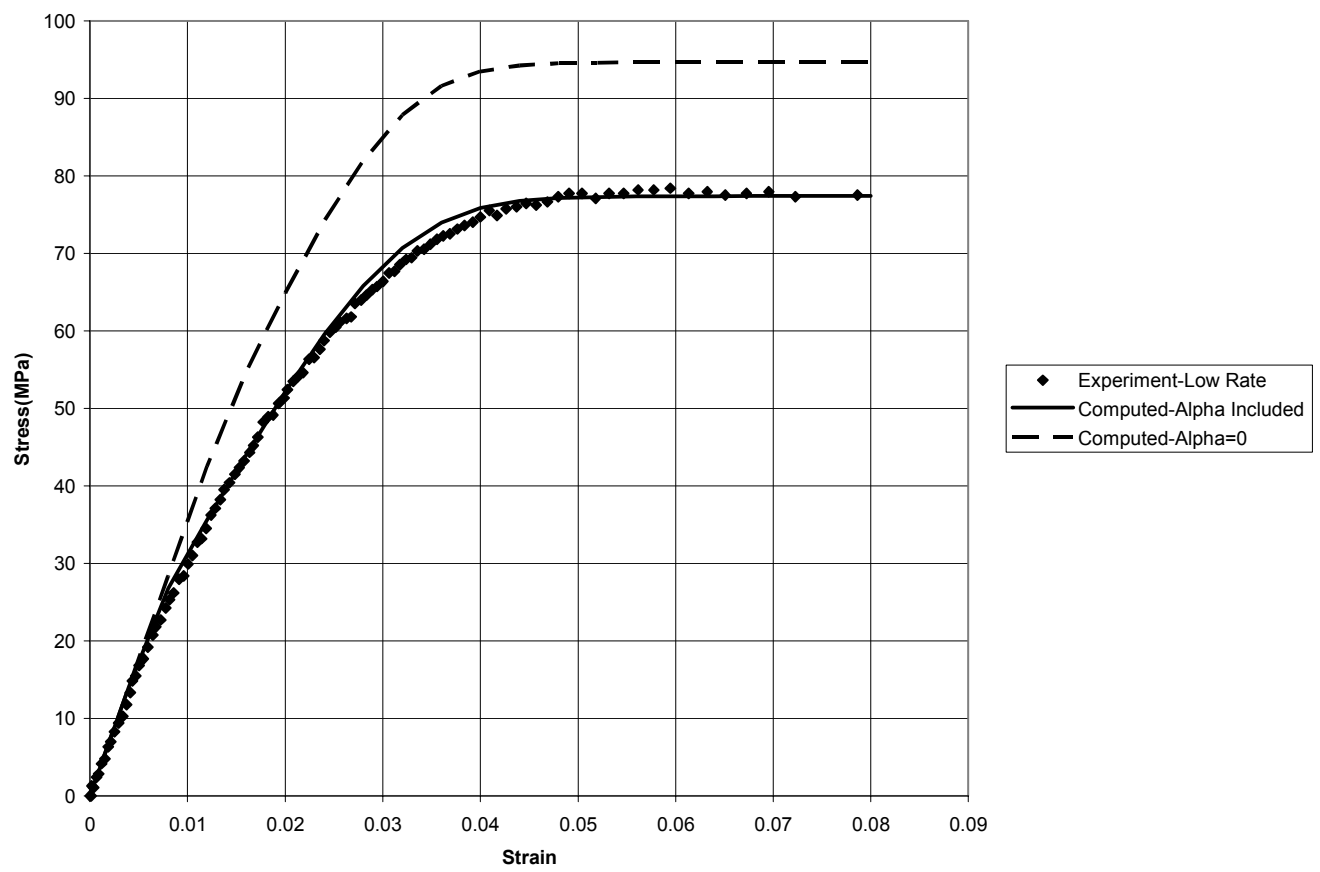

Figure 5.-Effect of hydrostatic stress effect state variable $\alpha$ on tensile stress-strain curve for PR520 resin at strain rate of $5 \times 10^{-5} / \mathrm{sec}$. 


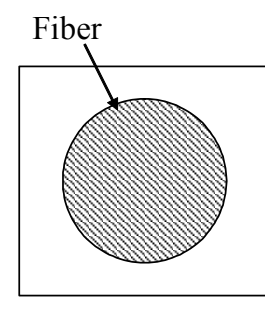

Unit Cell

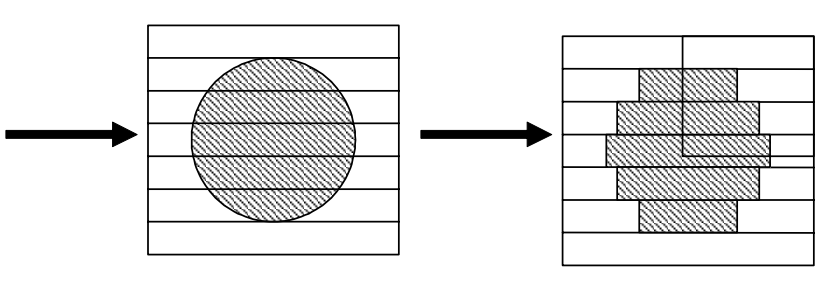

Sliced Unit Cell

Circular Fiber

Sliced Unit Cell

Rectangular Fiber Slices
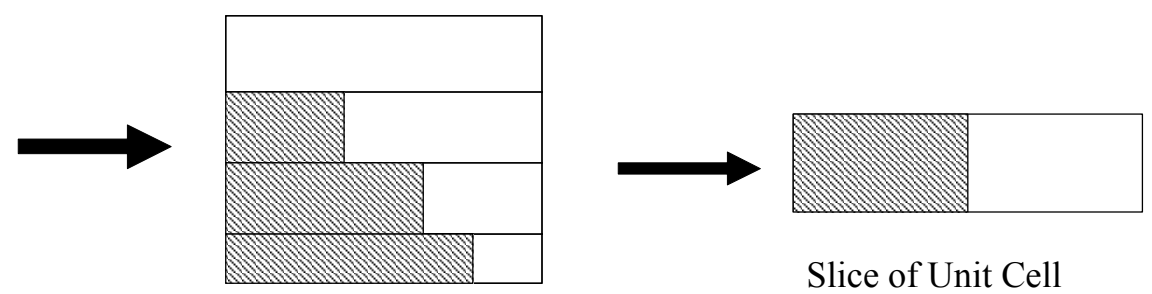

Slice of Unit Cell

Portion of Sliced Unit Cell Analyzed

Figure 6.-Schematic showing relationship between unit cell and slices for micromechanics.

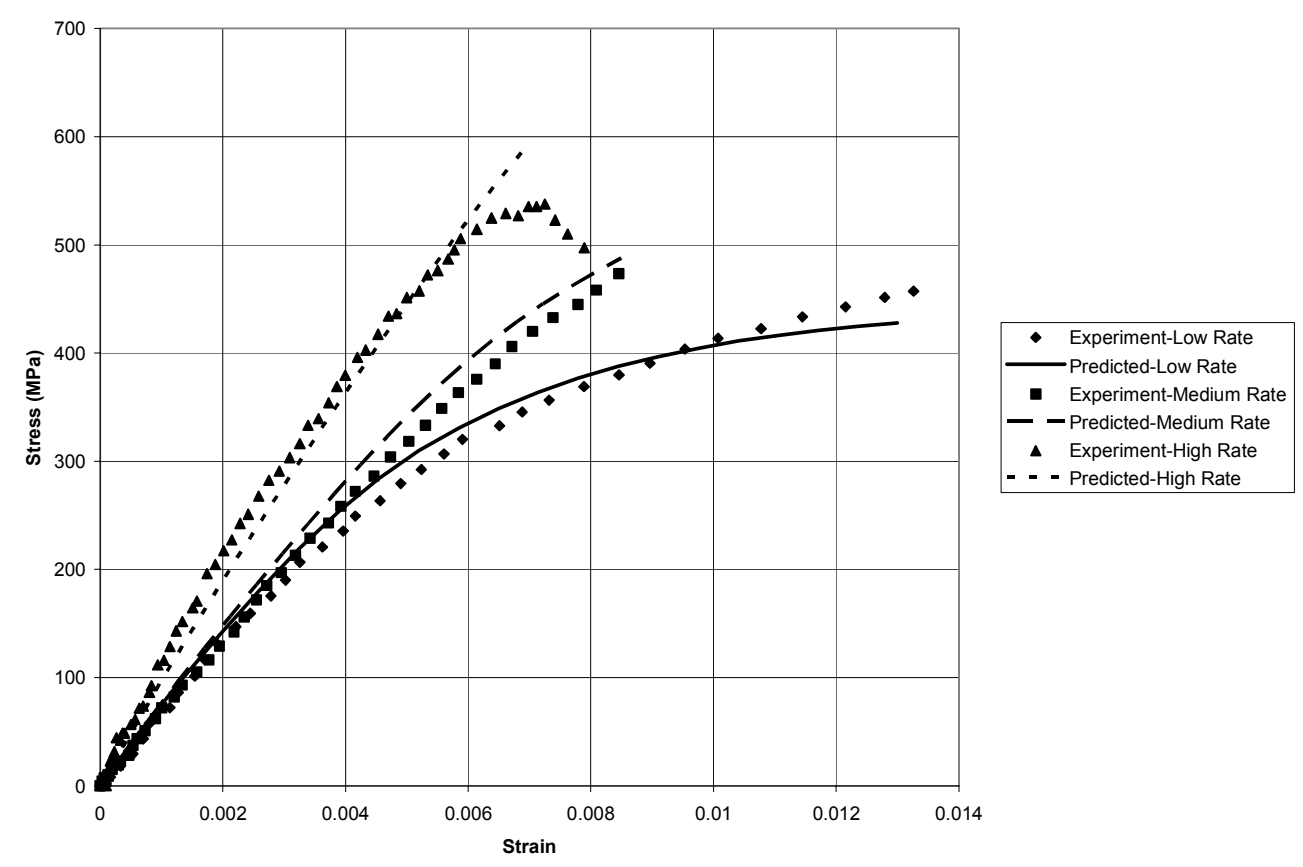

Figure 7.-Experimental and predicted stress-strain curves for IM7/977-2 [10 $]$ composite at strain rates of $1.8 \times 10^{-5} / \mathrm{sec}$ (Low Rate), $0.56 / \mathrm{sec}$ (Medium Rate) and $320 / \mathrm{sec}$ (High Rate). 


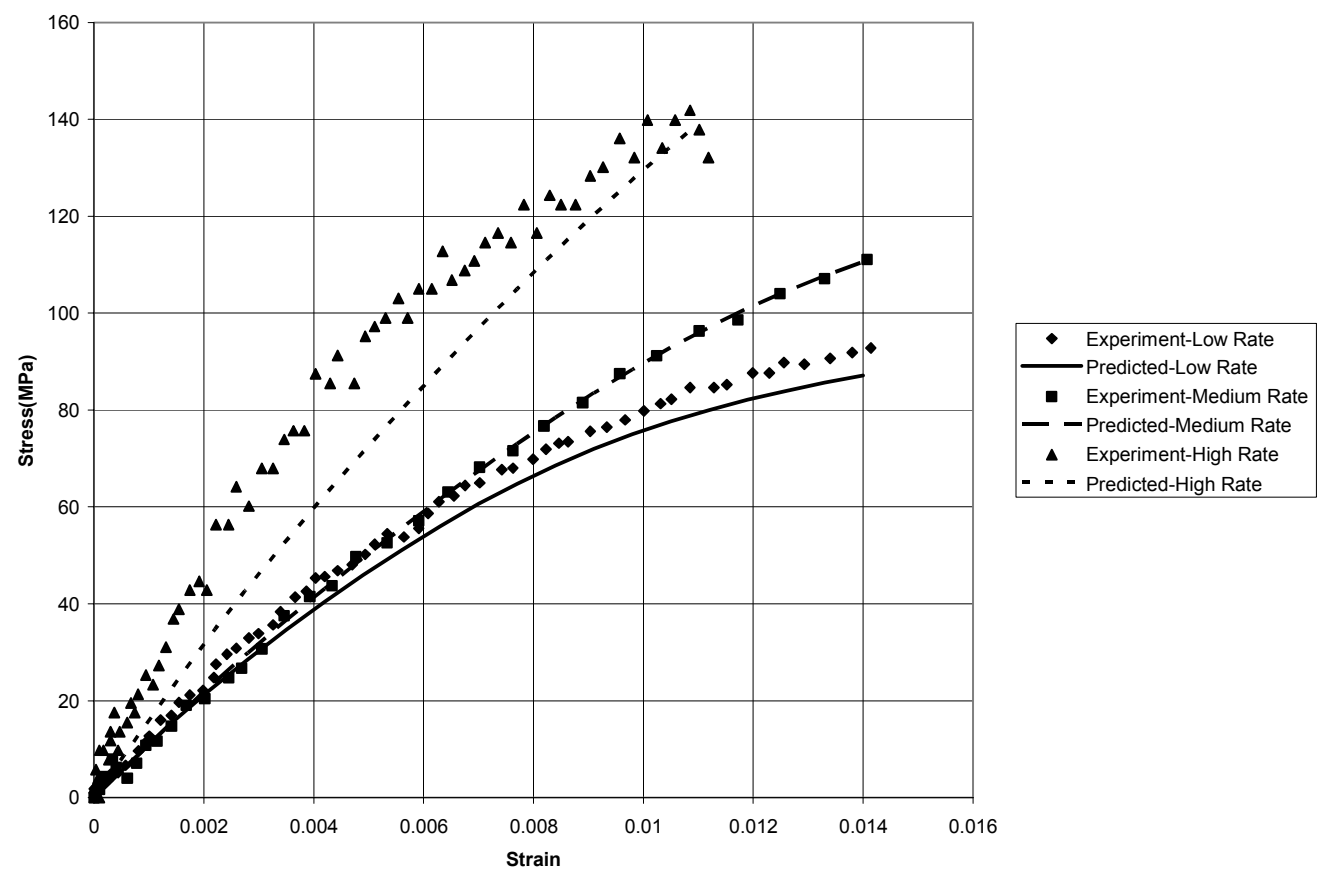

Figure 8.-Experimental and computed stress-strain curves for IM7/977-2 [45 $]$ composite at strain rates of $4.75 \times 10^{-5} / \mathrm{sec}$ (Low Rate), $1.2 / \mathrm{sec}$ (Medium Rate) and $405 / \mathrm{sec}$ (High Rate).

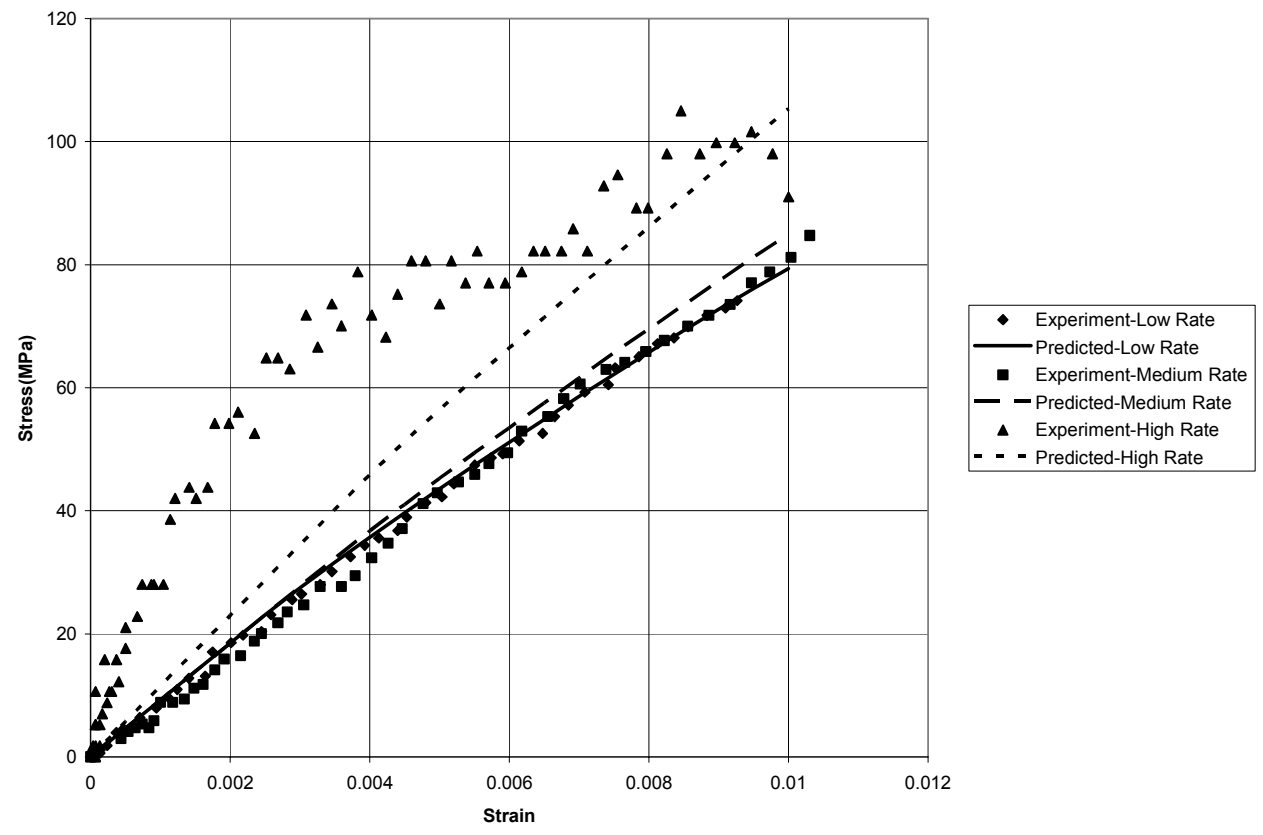

Figure 9.-Experimental and computed stress-strain curves for IM7/977-2 [90 ${ }^{\circ}$ composite at strain rates of $4.44 \times 10^{-5} / \mathrm{sec}$ (Low Rate), $1.09 / \mathrm{sec}$ (Medium Rate) and $405 / \mathrm{sec}$ (High Rate). 


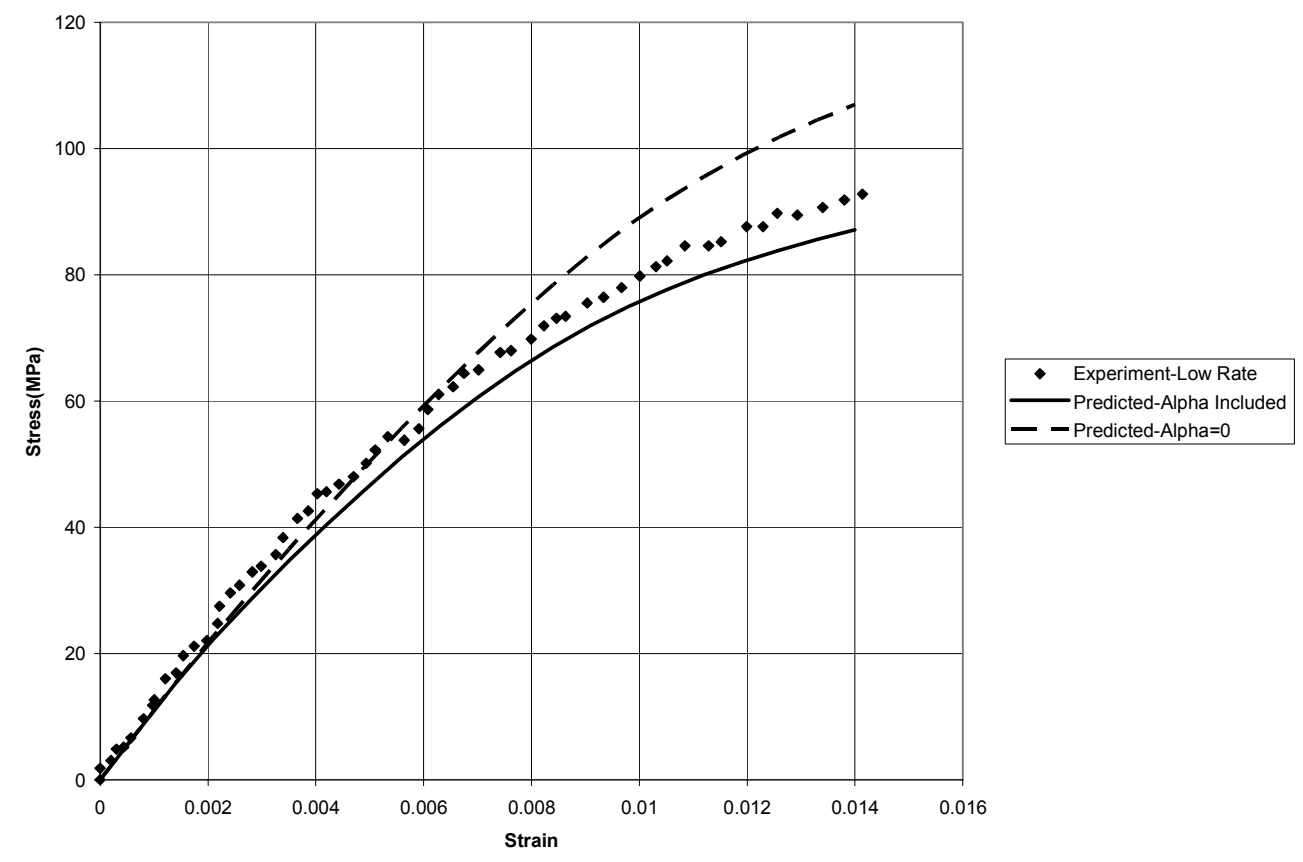

Figure 10.-Effect of hydrostatic stress effect state variable $\alpha$ on tensile stress-strain curve for IM7/977-2 [45 $]$ laminate at strain rate of $4.75 \times 10^{-5} / \mathrm{sec}$. 
Public reporting burden for this collection of information is estimated to average 1 hour per response, including the time for reviewing instructions, searching existing data sources, gathering and maintaining the data needed, and completing and reviewing the collection of information. Send comments regarding this burden estimate or any other aspect of this collection of information, including suggestions for reducing this burden, to Washington Headquarters Services, Directorate for Information Operations and Reports, 1215 Jefferson Davis Highway, Suite 1204, Arlington, VA 22202-4302, and to the Office of Management and Budget, Paperwork Reduction Project (0704-0188), Washington, DC 20503.

\begin{tabular}{|l|l|r|}
\hline 1. AGENCY USE ONLY (Leave blank) & $\begin{array}{c}\text { 2. REPORT DATE } \\
\text { June } 2003\end{array}$ & $\begin{array}{r}\text { 3. REPORT TYPE AND DATES COVERED } \\
\text { Technical Memorandur }\end{array}$
\end{tabular}

4. TITLE AND SUBTITLE

5. FUNDING NUMBERS

Implementation of an Associative Flow Rule Including Hydrostatic Stress Effects Into the High Strain Rate Deformation Analysis of Polymer Matrix Composites

6. AUTHOR(S)

WBS-22-708-24-05

Robert K. Goldberg, Gary D. Roberts, and Amos Gilat

7. PERFORMING ORGANIZATION NAME(S) AND ADDRESS(ES)

National Aeronautics and Space Administration

John H. Glenn Research Center at Lewis Field

Cleveland, Ohio 44135-3191

8. PERFORMING ORGANIZATION

REPORT NUMBER

E-13959

9. SPONSORING/MONITORING AGENCY NAME(S) AND ADDRESS(ES)

10. SPONSORING/MONITORING

AGENCY REPORT NUMBER

National Aeronautics and Space Administration

Washington, DC 20546-0001

NASA TM-2003-212382

11. SUPPLEMENTARY NOTES

Robert K. Goldberg and Gary D. Roberts, NASA Glenn Research Center; Amos Gilat, Ohio State University, Columbus, Ohio 43210. Responsible person, Robert K. Goldberg, organization code 5920, 216-433-3330.

12a. DISTRIBUTION/AVAILABILITY STATEMENT

12b. DISTRIBUTION CODE

Unclassified - Unlimited

Subject Category: 24

Distribution: Nonstandard

Available electronically at http://gltrs.grc.nasa.gov

This publication is available from the NASA Center for AeroSpace Information, 301-621-0390.

13. ABSTRACT (Maximum 200 words)

A previously developed analytical formulation has been modified in order to more accurately account for the effects of hydrostatic stresses on the nonlinear, strain rate dependent deformation of polymer matrix composites. State variable constitutive equations originally developed for metals have been modified in order to model the nonlinear, strain rate dependent deformation of polymeric materials. To account for the effects of hydrostatic stresses, which are significant in polymers, the classical $\mathrm{J}_{2}$ plasticity theory definitions of effective stress and effective inelastic strain, along with the equations used to compute the components of the inelastic strain rate tensor, are appropriately modified. To verify the revised formulation, the shear and tensile deformation of two representative polymers are computed across a wide range of strain rates. Results computed using the developed constitutive equations correlate well with experimental data. The polymer constitutive equations are implemented within a strength of materials based micromechanics method to predict the nonlinear, strain rate dependent deformation of polymer matrix composites. The composite mechanics are verified by analyzing the deformation of a representative polymer matrix composite for several fiber orientation angles across a variety of strain rates. The computed values compare well to experimentally obtained results.

14. SUBJECT TERMS 15. NUMBER OF PAGES

Polymer matrix composites; Constitutive equations; Strain rate; Viscoplasticity; Impact; Micromechanics

17. SECURITY CLASSIFICATION OF REPORT

Unclassified
18. SECURITY CLASSIFICATION OF THIS PAGE

Unclassified
19. SECURITY CLASSIFICATION OF ABSTRACT

Unclassified 